\title{
Percepções da comunidade moçambicana bilíngue em relação ao uso do português e das línguas maternas Bantu
}

\author{
Perceptions of the bilingual \\ Mozambican community \\ regarding the use of Portuguese \\ and Bantu mother languages
}

David Alberto Seth Langa ${ }^{1}$

https://orcid.org/0000-0002-3887-2539

Resumo: O presente estudo pretende averiguar se o bilinguismo em Moçambique está, ou não, a dar origem ao declínio e abandono das línguas bantu locais. Especificamente, visa identificar factores de erosão ambiental: atitudes para com as LB/L1 e LP/L2 e a vitalidade das LB. A comunidade moçambicana bilíngue quase duplicou, de pouco mais de $20 \%$, em 1980, para cerca de 40\% da população total em 2017 (INE, 2009; FIRMINO, 2000; CHIMBUTANE, 2012; INE, 2019). Considerando que o uso de uma língua desenvolve no falante uma certa avaliação sobre a imagem que pretende criar de si mesmo (ROMAINE, 1995; PAUWELS, 2004), bem como a definição de identidade (kind of person) de um indivíduo (GEE, 2000), esses dados sugerem que, em Moçambique, se está a desenhar um cenário de mudança de língua, das línguas bantu para o Português. Os dados colhidos de 270 estudantes universitários de três cidades, distribuídos em quatro áreas educacionais, conforme ISCED (2011), permitem concluir que esta geração convive de forma harmoniosa com o seu bilinguismo. Quanto à identidade político-cultural, estes não se sentem discriminados como cidadãos moçambicanos pelo facto

\footnotetext{
${ }^{1}$ Universidade Eduardo Mondlane (Moçambique). E-mail: daslanga@gmail.com
} 
de falarem Português, mas tendem a considerar que o domínio de uma língua bantu os torna cidadãos mais genuinamente moçambicanos.

Palavras-Chave: atitudes linguísticas, identidade linguística, bilinguismo, Moçambique

Abstract: This study aims to ascertain whether bilingualism in Mozambique is, or not to give rise to the decline and abandonment of the local bantu languages. Specifically, the study aims to identify environmental erosion factors: attitudes towards LB / L1 and LP / L2, and the vitality of LB. The bilingual Mozambican community almost doubled from just over 20\% in 1980 to about $40 \%$ of the total population in 2007 (INE, 2009, FIRMINO, 2000, CHIMBUTANE, 2012, INE, 2019). Based on the principle that the use of a language develops in the speaker a certain evaluation of the image he/she intends to create of himself/herself (ROMAIN, 1995; PAUWELS, 2004), as well as the definition (kind of person) of individuals (GEE, 2000), these data may mean that in Mozambique a scenario of language change is being designed for Portuguese. The data collected from 270 higher education students from three cities, distributed according to the $\mathrm{g}$ educational areas (ISCED, 2011, concludes that this generation coexists harmoniously with their bilingualism. Regarding political-cultural identity, more specifically, respondents do not feel discriminated against as Mozambican citizens because they speak Portuguese, but tend to consider that mastery of a Bantu language makes them more genuinely Mozambican citizens

Keywords: language attitudes, linguistic identity, bilingualism, Mozambique

\section{Introdução}

O presente artigo surge no âmbito de um projecto maior hospedado na Cátedra de Português: Língua Segunda e Estrangeira, intitulado "Comunidade Moçambicana Bilíngue com Língua Bantu/L1 e Português/L2: Estudo Exploratório", da Universidade Eduardo Mondlane, em Moçambique.

O objectivo geral do estudo é, através da análise das percepções sobre uso da língua portuguesa/língua segunda (doravante LP/L2) e da língua materna bantu² (doravante LB/L1) da comunidade moçambicana bilíngue, averiguar se o bilinguismo em Moçambique está, ou não, a dar origem ao declínio e abandono das línguas bantu locais. Especificamente, o estudo visa identificar factores de erosão ambiental: atitudes para com as LB/L1 e LP/L2, e a vitalidade das LB.

A comunidade moçambicana bilíngue quase duplicou, de pouco mais de $20 \%$, em

\footnotetext{
${ }^{2}$ Línguas bantu pertencem à subfamília Niger-Congo da família Congo-Kodorfaniana (cf. NGUNGA, 2004). Existem várias formas de se referir e escrever essas línguas bantu. Uns escrevem bantu e outros banto. Uns as designam de línguas bantu e outros de línguas africanas. Sem querer argumentar sobre uma ou outra forma, no presente artigo adopta-se a designação língua bantu e a escrita das línguas é a padronizada e adoptada em Moçambique por Nelmo (1989); Sitoe e Ngunga (2000) e Ngunga e Faquir (2011). Assim, sempre que aparecem no texto estarão representadas em itálico, como se apresenta na Tabela 2, do presente texto.
} 
1980, para cerca de 40\% da população total em 2007 (INE, 2009; FIRMINO, 2000; CHIMBUTANE, 2012). Partindo do princípio segundo o qual o uso de uma língua desenvolve no falante uma certa avaliação sobre a imagem que pretende criar de si mesmo (ROMAINE, 1995; SKUTNABB-KANGAS, 1981; PAUWELS, 2004), bem como a definição de identidade (kind of person) de um indivíduo (GEE, 2000), estes dados podem significar que, em Moçambique, se está a desenhar um cenário de mudança de língua para o Português, com consequente abandono das línguas bantu.

As atitudes dos inquiridos são favoráveis à LP mas manifestam o desejo de preservar/manter a sua LB. Os inquiridos consideram que falar a LP/L2 ou a LB/L1 tem pouco a ver com o facto de os falantes se sentirem ou não civilizados. Da mesma forma que os inquiridos não se sentem tribalistas por eles falarem e/ou outro não falar a sua LB. Contudo, tendem a considerar menos inteligentes os que não falam a LP. Esse dado revela a necessidade de se continuar a desenvolver no país acções visando o contínuo uso da LB/L1 na educação formal (ensino bilíngue), nos espaços públicos oficiais ou de estado, e em outros locais comummente associados ao domínio da LP. De um modo geral, tanto o uso da LP/ L2 como da LB/ L1 são avaliados positivamente pelos inquiridos, apontando, assim, para uma geração que convive de forma harmoniosa com o seu bilinguismo. Quanto à identidade político-cultural, mais especificamente, os inquiridos não se sentem discriminados como cidadãos moçambicanos pelo facto de falarem Português, mas tendem a considerar que o domínio de uma língua bantu os torna cidadãos mais genuinamente moçambicanos.

O estudo tem a limitante de ser exploratório e nessa qualidade, ainda que feita em instituições do ensino superior pelas razões acima apresentadas, os resultados da amostra podem não reflectir a realidade das outras oito cidades capitais de Moçambique. Mesmo assim, considera-se que o estudo lança linhas de pesquisa que podem ser replicadas nas outras cidades.

O presente artigo está organizado da seguinte maneira: depois da introdução, apresenta-se a metodologia, seguida de "breves notas sobre a situação linguística de Moçambique", em que se apresenta a diversidade linguística e o estatuto das línguas faladas em Moçambique. Em seguida, apresenta-se a revisão de literatura e depois a análise e discussão de dados. Finalmente, apresentam-se as conclusões. 


\section{Metodologia}

O público-alvo do estudo é a "geração do pós-independência", tendo como pressuposto que o comportamento linguístico dessa geração pode ser ou ter sido influenciado pela educação familiar e tipo de socialização por que passou, com particular destaque para as atitudes e percepções dos pais em relação à importância/valor do Português e das línguas bantu, as quais podem ter condicionado a escolha da(s) língua(s) transmitida(s) à geração seguinte. Note-se que, historicamente, os pais dessa geração (i.e. nascidos no período colonial) eram interditos de usar as suas línguas maternas em contextos formais, sendo estas relegadas a domínios informais. Esta condição pode ter influenciado esses pais a não transmitir as suas LB/L1 aos seus filhos em favor da LP, por ser a língua oficialmente aceite (cf. CHIMBUTANE, 2012).

O estudo adoptou uma abordagem quantitativa, tendo como base a aplicação do questionário. A escolha dessa abordagem prende-se ao facto de o estudo ser de natureza "exploratória" e ser inédito no contexto moçambicano, bem como o estudo piloto que antecede este artigo, o Langa, Gonçalves e Tembe, 2014, a literatura existente (FISHMAN, 1967, 1972; ROMAINE, 1995; BATIBO, 2012) e contextos bilíngues e multilingues ter possibilitado identificar categorias/variáveis que se considerou serem válidas (e suficientes) para o estudo da comunidade moçambicana bilíngue.

\subsection{Público-alvo}

A amostra foi constituída por 270 estudantes universitários bilíngues, de diversos cursos/universidades dos centros urbanos de Maputo-Cidade, Xai-Xai e Quelimane. Em cada centro urbano, os questionários foram aplicados a estudantes de várias áreas educacionais (ISCED, 2011), que frequentavam o $2^{\circ}$ ano dos cursos de licenciatura em diferentes universidades, distribuídos pelas seguintes áreas educacionais:

(i) Área de Ciências Humanas: cursos de Ensino de Português e de Filosofia

(ii) Área de Ciências da Vida: curso de Biologia

(iii) Área de Gestão e Negócios: curso de Gestão

(iv) Área de Ciências Físicas: curso de Ciências Marinhas

Todos os inquiridos têm uma língua bantu (veja o ponto 2) como língua materna e o Português como língua segunda. 


\subsection{Locais de recolha de dados}

Como acima se referiu, os dados foram recolhidos em três cidades, a saber: Maputo, Xai-Xai e Quelimane. A escolha de Maputo-Cidade baseou-se no facto de ser um centro urbano relativamente complexo. Assim, do ponto de vista linguístico, salienta-se o facto de a sua população ter várias línguas bantu como L1: de acordo com dados do Censo de 2007, além do Changana e do Ronga (faladas por $31.5 \%$ e $9.7 \%$ da população, respectivamente), são ainda faladas outras línguas bantu, como por exemplo: Chitswa, Gitonga, Copi, Makhuwa, Makonde, Sena, etc. (CHIMBUTANE, 2012). No que se refere às atitudes dos falantes para com o Português e as línguas bantu, pode considerar-se que existem também várias "zonas" distintas, em que se observa, de acordo com FIRMINO (2002), a tendência de preservar as línguas maternas bantu, como posturas de tipo "assimilacionista" relativamente ao Português.

A escolha de Xai-Xai decorreu, por um lado, do facto de essa cidade estar situada numa zona linguística bastante homogénea do ponto de vista sociolinguístico. Assim, no que respeita às línguas maternas, os dados do Censo de 2007 indicam que a grande maioria da população da província de Gaza (87.2\%) tem o Changana como L1 (CHIMBUTANE, 2012). Por outro lado, ainda que não tenham sido realizados estudos sobre as atitudes linguísticas dos falantes de Xai-Xai, existe a percepção generalizada de que a população dessa cidade tem uma forte atitude positiva relativamente às línguas bantu.

Na escolha de Quelimane, tomou-se em consideração não só o facto de essa cidade estar situada numa zona linguística em que são faladas línguas bantu distintas dos outros dois centros urbanos seleccionados, como também a percepção de que as atitudes dos falantes para com o Português e as línguas bantu são distintas. Do ponto de vista linguístico, os dados do Censo de 2007 indicam que, na província da Zambézia, as L1 dominantes são o Lomwe e o Chuwabo - 37.1\% e 23.5\%, respectivamente (CHIMBUTANE, 2012). Ainda que não tenham sido realizados estudos sobre as atitudes linguísticas dos falantes dessa cidade, existe a percepção generalizada de que a sua população tem uma atitude de tipo "assimilacionista" relativamente ao Português, contrastando assim com a atitude da maior parte dos residentes de Xai-Xai. 


\subsection{Instrumento de recolha de dados}

Os dados foram recolhidos através de um questionário aplicado a 270 inquiridos, conforme descrito em 1.1. O questionário encontra-se organizado em 8 grupos, enumerados de $\mathrm{A}$ a $\mathrm{H}$, conforme o Quadro 1, que se segue:

Quadro 1: Estrutura geral do inquérito

\begin{tabular}{|c|c|c|c|}
\hline Grupo & Grupo temático & Objectivo & $\begin{array}{l}\mathrm{N}^{\mathrm{O}} \mathrm{de} \\
\text { questões }\end{array}$ \\
\hline $\mathrm{A}$ & Perfil sociolinguístico & $\begin{array}{l}\text { Colher alguma informação sociolinguistica do } \\
\text { inquirido }\end{array}$ & 8 \\
\hline $\mathrm{B}$ & Autobiografia linguística & $\begin{array}{l}\text { Colher alguma informação sobre as línguas do } \\
\text { inquirido }\end{array}$ & 5 \\
\hline $\mathrm{C}$ & Contextos de uso & $\begin{array}{l}\text { Colher informações sobre os contextos em que } \\
\text { usa o Português e a sua língua materna bantu } \\
\text { (i.e. as pessoas com quem fala, os lugares e as } \\
\text { circunstâncias em que usa essas línguas e os } \\
\text { assuntos de que fala. }\end{array}$ & 5 \\
\hline $\mathrm{D}$ & $\begin{array}{l}\text { Percepções em relação ao } \\
\text { uso }\end{array}$ & $\begin{array}{l}\text { Obter informações sobre como o inquirido se } \\
\text { sente quando comunica em Português e em sua } \\
\text { língua materna bantu }\end{array}$ & 18 \\
\hline $\mathrm{E}$ & $\begin{array}{l}\text { Percepções em relação à } \\
\text { importância } \\
\text { conhecimento e uso do } \\
\text { Português e da sua língua } \\
\text { materna bantu }\end{array}$ & $\begin{array}{l}\text { Obter informações sobre a importância que o } \\
\text { inquirido atribui ao conhecer e usar Português } \\
\text { e a sua língua materna bantu }\end{array}$ & 26 \\
\hline $\mathrm{F}$ & $\begin{array}{ll}\text { Percepções } & \text { sobre } a \\
\text { vitalidade da sua língua } \\
\text { materna bantu }\end{array}$ & $\begin{array}{l}\text { Saber a opinião do inquirido sobre a sua } \\
\text { percepção quanto à continuidade de sua língua } \\
\text { materna bantu ser falada por muito mais tempo } \\
\text { em Moçambique }\end{array}$ & 14 \\
\hline$G$ & $\begin{array}{lcr}\text { Percepções } & \text { sobre } & \text { o } \\
\text { conhecimento } & \text { da } & \text { sua } \\
\text { língua materna bantu } & \end{array}$ & $\begin{array}{l}\text { Colher informações sobre o que acontece } \\
\text { quando o inquirido comunica na sua língua } \\
\text { materna bantu }\end{array}$ & 12 \\
\hline $\mathrm{H}$ & $\begin{array}{l}\text { Opinião sobre a } \\
\text { transmissão do Português } \\
\text { e/ou das línguas bantu à } \\
\text { geração seguinte }\end{array}$ & $\begin{array}{l}\text { Colher a opinião do inquirido sobre a } \\
\text { possibilidade da transmissão do Português e/ou } \\
\text { das línguas bantu aos seus filhos (geração } \\
\text { seguinte) }\end{array}$ & 3 \\
\hline
\end{tabular}




\begin{tabular}{|l|l|}
\hline Total & 91 \\
\hline
\end{tabular}

Surgindo de um projecto maior, como se referiu na introdução, o presente artigo analisa os dados do Grupo D, cujos objectivos constam do Quadro 1. Esse grupo insere dois grupos de questões: (i) questões sobre atitudes linguísticas e (ii) questões sobre identidade linguística. Adoptou-se a escala de Likert e todas as opções respondem à seguinte pergunta do inquérito: "Diga se está TOTALMENTE DE ACORDO, DE ACORDO, INDECISO, EM DESACORDO OU TOTALMENTE EM DESACORDO em relação às afirmações que se seguem: (quando fala na língua portuguesa-L2 /sua língua materna bantu, sente-se:)".

Em relação às atitudes linguísticas, as duas línguas têm em comum o seguinte grupo de respostas que correspondem a auto-avaliação: sente-se "orgulhoso/a", "mais inteligente", "pessoa civilizada" e "pessoa envergonhada", diferindo em relação à língua portuguesa-L2, da opção "instruída" e, para a língua materna bantu, a opção "tribalista ou regionalista".

Em relação à identidade linguística, em relação à LP, as afirmações sobre a identidade são "Quando fala na língua portuguesa sente-se: superior a outros moçambicanos que não falam esta língua; menos moçambicano; como um(a) cidadão(ã) português(a); estrangeiro/a no seu próprio país"; ao passo que, para as LBs, as afirmações/as variáveis eram as seguintes "superior a outros jovens do seu grupo etnolinguístico que não falam esta língua e um(a) moçambicano(a) mais genuíno(a)".

\subsection{Perfil sociolinguístico dos inquiridos}

Os dados do perfil dos inquiridos nas três cidades resultam da recolha de dados. No presente artigo vão-se analisar três principais variáveis, a saber: idade, sexo e língua materna dos inquiridos, conforme a Tabela 1 abaixo:

Quadro 2: Perfil dos inquiridos das cidades estudadas

\begin{tabular}{|c|c|c|c|c|c|c|c|c|c|}
\hline \multirow[t]{3}{*}{ Variável } & & \multicolumn{6}{|c|}{ Cidade } & \multirow{2}{*}{\multicolumn{2}{|c|}{ Total }} \\
\hline & & \multicolumn{2}{|c|}{ Maputo } & \multicolumn{2}{|c|}{ Xai-Xai } & \multicolumn{2}{|c|}{ Quelimane } & & \\
\hline & & $\mathrm{Fr}$ & $\%$ & $\mathrm{Fr}$ & $\%$ & $\mathrm{Fr}$ & $\%$ & $\mathrm{Fr}$ & $\%$ \\
\hline \multirow[t]{3}{*}{ Idade } & $18-24$ & 54 & 56.3 & 34 & 39.5 & 52 & 59.1 & 140 & 51.9 \\
\hline & $25-40$ & 25 & 26.0 & 42 & 48.8 & 25 & 28.4 & 92 & 34.1 \\
\hline & Mais de 40 & 2 & 2.1 & 1 & 1.2 & 0 & 0.0 & 3 & 1.1 \\
\hline
\end{tabular}




\begin{tabular}{|c|c|c|c|c|c|c|c|c|c|}
\hline & $N / R$ & 15 & 15.6 & 9 & 10.5 & 11 & 12.5 & 35 & 13.0 \\
\hline \multicolumn{2}{|l|}{ Total } & 96 & 100 & 86 & 100 & 88 & 100 & 270 & 100 \\
\hline \multirow[t]{2}{*}{ Sexo } & $F$ & 46 & 47.9 & 44 & 51.2 & 32 & 36.4 & 122 & 45.2 \\
\hline & $M$ & 50 & 52.1 & 42 & 48.8 & 56 & 63.6 & 148 & 54.8 \\
\hline \multicolumn{2}{|l|}{ Total } & 96 & 100 & 86 & 100 & 88 & 100 & 270 & 100 \\
\hline \multirow{5}{*}{ Língua Materna } & Ronga & 17 & 17.7 & 6 & 7.0 & 2 & 2.3 & 25 & 9.3 \\
\hline & Changana & 56 & 58.3 & 60 & 69.8 & 4 & 4.5 & 120 & 44.4 \\
\hline & Chuwabo & 0 & 0.0 & 1 & 1.2 & 36 & 40.9 & 37 & 13.7 \\
\hline & Outra & 14 & 14.6 & 9 & 10.5 & 42 & 47.7 & 65 & 24.1 \\
\hline & N/R & 9 & 9.4 & 10 & 11.6 & 4 & 4.5 & 23 & 8.5 \\
\hline \multicolumn{2}{|l|}{ Total } & 96 & 100 & 86 & 100 & 88 & 100 & 270 & 100 \\
\hline
\end{tabular}

No que tange à variável idade, nas Cidades de Maputo e Quelimane, o Quadro 2 mostra que mais da metade dos inquiridos tem idades compreendidas entre os 18-24 anos, com $56.3 \%$ e $59.1 \%$, respectivamente, ao passo que, na Cidade de Xai-Xai, a percentagem é de $39.5 \%$. No geral, a faixa etária dos 18-24 anos é que domina a amostra.

Em relação à variável sexo, a maior parte dos inquiridos são do sexo masculino (54.8\%), sendo a Cidade de Quelimane onde grande parte dos inquiridos são do sexo masculino (63.6\%), seguida da Cidade de Maputo, com pouco mais da metade de inquiridos do sexo masculino (52.1\%). Diferente dessas duas cidades, na Cidade de Xai-Xai predominam inquiridos do sexo feminino $(51.2 \%)$.

Sendo a população em estudo bilíngue, com a LB/L1 e LP/L2, quanto à sua língua materna, no geral, uma percentagem considerável dos inquiridos são falantes do Changana (44.4\%), sendo que as Cidades de Maputo e de Xai-Xai são as que apresentam a maior percentagem de falantes desta língua. A Cidade de Xai-Xai é a que mais se destaca, com grande parte dos inquiridos falantes desta língua (69.8\%), seguida da Cidade de Maputo, com cerca da metade dos inquiridos (58.3\%). A presença de mais falantes do Changana na Cidade de Maputo, uma cidade tradicionalmente nativa de falantes Ronga, parece ser um indicador de que essa língua tende progressivamente a deixar de ser a mais falada no seu território, dando lugar a um cada vez mais crescente uso do Changana (CHIMBUTANE, 2012). Na Cidade de Quelimane, uma percentagem considerável de inquiridos (40.9\%) é falante de Chuabo. Para além das línguas maternas acima referidas por cidade, uma percentagem reduzida dos inquiridos $(24.1 \%)$ afirma falar uma outra língua materna bantu, que distribui-se em percentagens irrelevantes (abaixo de 10\%) dentre as línguas faladas em Moçambique no geral, sendo as línguas Tshwa 
(5.6\%) e Chope (3.3\%) as que se destacam desse universo. Os dados apontam que esta cidade é linguisticamente heterogénea com percentagem reduzida de falantes das diversas línguas da região, como é o caso das línguas Makhuwa, Sena e o Tonga e Tshwa, dentre outras, que são faladas em outras regiões de Moçambique.

\section{Breves notas sobre a situação linguística de Moçambique}

Moçambique é comumente definido como

um país multilingue e multicultural (não apenas multi-étnico). Para além do Português, que é a língua oficial, e das línguas asiáticas (como o Gujarate, Memane, Hindi e Urdu), que são faladas nativamente por vários moçambicanos, a grande maioria das línguas faladas em Moçambique pertence ao grupo Bantu. Estas são línguas indígenas e constituem o principal estrato linguístico, tanto com respeito ao número de falantes como em termos da distribuição das línguas pelo território. (LOPES, 2004, p. 18).

O Quadro 3 apresenta um panorama geral da distribuição das línguas moçambicanas faladas pela população de 5 ou mais anos de idade.

Quadro 3: Distribuição de línguas faladas pela população de 5 ou mais anos de idade

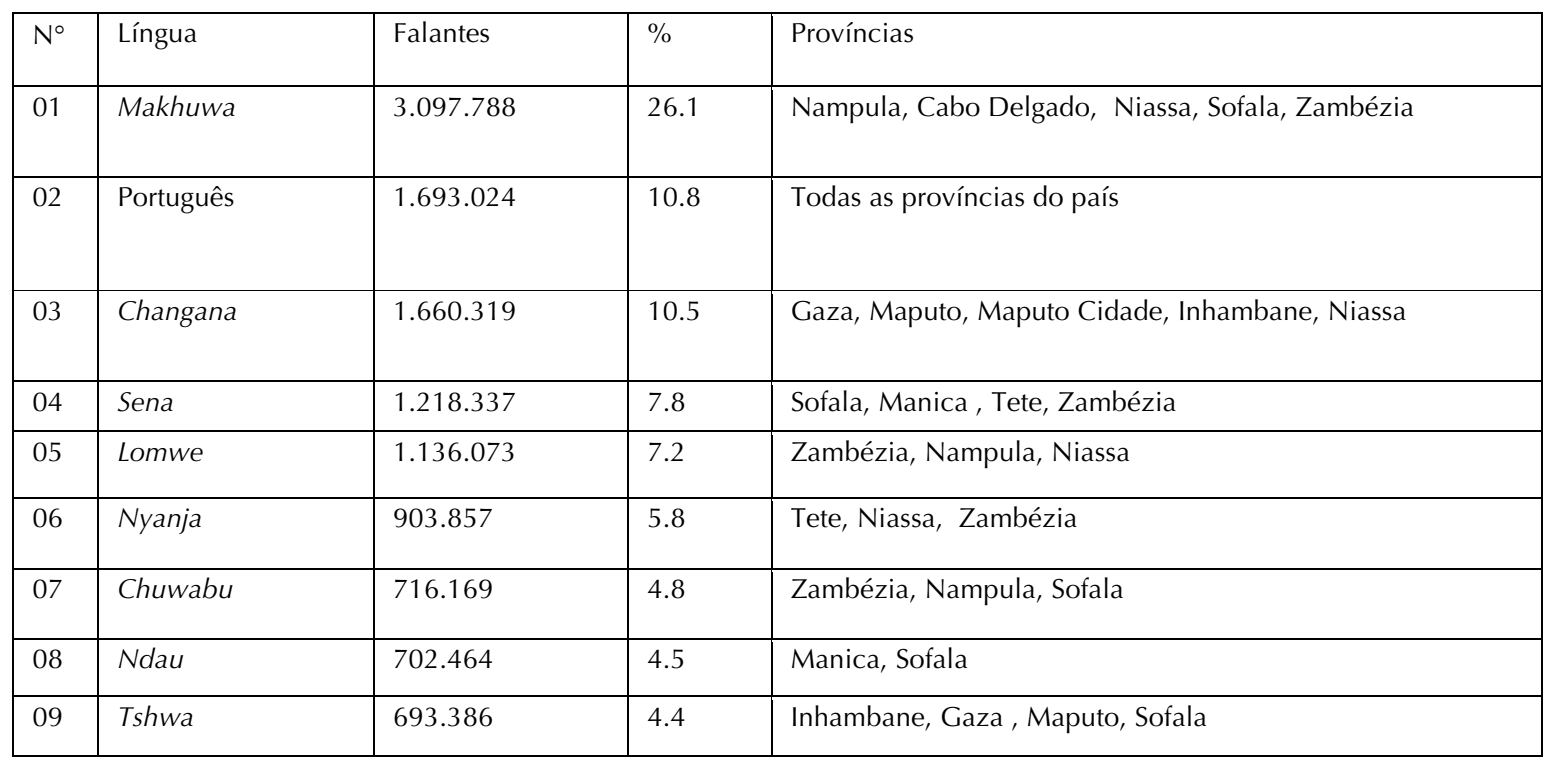




\begin{tabular}{|l|l|l|l|l|}
\hline 10 & Nyungwe & 457.292 & 2.9 & Tete, Manica \\
\hline 11 & Yaawo & 341.796 & 2.2 & Niassa, Cabo Delgado \\
\hline 12 & Copi & 303.740 & 1.9 & Gaza, Inhambane, Maputo, Cidade de Maputo \\
\hline 13 & Makonde & 268.910 & 1.7 & Cabo Delgado \\
\hline 14 & Tewe & 259.790 & 1.7 & Manica \\
\hline 15 & Rhonga & 235.829 & 1.5 & Maputo, Cidade de Maputo, Gaza, Inhambane \\
\hline 16 & Tonga & 227.256 & 1.5 & Inhambane, Gaza, Maputo, Cidade de Maputo \\
\hline 17 & Manyika & 133.961 & 0.9 & Manica \\
\hline 18 & Cibalke & 112.852 & 0.7 & Manica \\
\hline 19 & Mwani & 77.915 & 0.5 & Cabo Delgado \\
\hline 20 & Koti & 60.771 & 0.4 & Nampula \\
\hline 21 & Shona & 35.878 & 0.2 & Manica \\
\hline 22 & Swahili & 15.255 & 0.1 & Cabo Delgado \\
\hline 23 & Línguas de Sinais & 7.503 & 0.05 & Todas Províncias \\
\hline
\end{tabular}

Ngunga \& Bavo (2011, p.14-15).

De uma forma geral, excepto o Português, as línguas moçambicanas são línguas minoritárias, onde, sem contar com Makhuwa (26.1\%), Changana (10.5\%), Sena (7.8\%) e Lomwe (7.2), todas as outras têm percentagem de falantes abaixo de (6\%). Segundo Batibo (2012), sociolinguisticamente, a língua minoritária não é apenas definida pela sua relativa inferioridade demográfica, mas também, e sobretudo, pela sua função pública limitada. Assim, a língua minoritária pode ser definida horizontalmente e verticalmente: (i) Horizontalmente: olhando a sua fraqueza em relação a outras línguas na região ou nação; (ii) Verticalmente: com base no estatuto baixo ("low status") e a ausência do uso público ou uma área oficial. Tendo em conta estes dois domínios, muitas línguas africanas são designadas minoritárias do ponto de vista da sua relativa demografia e inferioridade socioeconômica. Muitas são confinadas a comunicação no nível familiar ou da comunidade. Assim, as línguas ex-coloniais, embora sejam 
faladas apenas por uma minoria instruída, em muitos países, não são consideradas línguas minoritárias.

Sem contar com a língua portuguesa, que é a língua oficial (cf. Artigo 10, da Constituição da República de Moçambique) por isso a sua vitalidade garantida, as línguas bantu são usadas na comunicação quotidiana intraétnica, mais usadas em zonas rurais (i.e. nas zonas urbanas são usadas juntamente com o Português), não têm estatuto oficial explícito e aparecem em vários documentos e/ou discursos como repositórios da herança cultural moçambicana (FIRMINO, 2002).

\section{Revisão de Literatura}

O bilinguismo constitui uma complexa área multidimensional, que envolve aspectos linguísticos, psicológicos, socioculturais, educacionais, etc., que têm atraído investigadores de todo o mundo desde os anos 30 do século passado (cf. o estudo pioneiro de Bloomfield (1933)). No presente artigo, adopta-se a definição que Mohanty \& Perregaux (1997) dão para bilíngues: indivíduos ou grupos de pessoas com habilidades comunicativas, vários graus de proficiência, no nível oral e/ou escrito, que os possibilita a interagir com falantes de uma ou mais línguas numa dada sociedade. Ainda que esteja já disponível um conjunto considerável de estudos sobre diversos aspectos do contacto entre as línguas bantu e o Português em Moçambique, até hoje não foi realizada uma pesquisa sistemática que tome como alvo central a importante faixa da comunidade moçambicana, a comunidade bilíngue.

Os estudos existentes debruçam-se sobre aspectos sociolinguísticos do bilinguismo em Moçambique (cf. GUISSEMO, 2018; FIRMINO, 2002), sobre o uso das línguas maternas bantu na educação e políticas adoptadas pelo Governo de Moçambique (cf. CHIMBUTANE, 2011; DIAS, 2008), estudos sobre o léxico, como o resultado do encontro das línguas maternas bantu com o Português (cf. SITOE, 1991; REGO, 2000; DIAS, 2002; LOPES et al, 2002; MACHUNGO, 2016), bem como estudos sobre o papel das línguas maternas bantu na formação da variedade do português de Moçambique (GONÇALVES, 2004, 2010; ASHBY \& BARBOSA, 2011; NGUNGA, 2012, entre outros)

Numa outra perspectiva, um conjunto considerável de estudos sobre a situação linguística moçambicana dedica-se a questões de política linguística, apresentando um conjunto amplo de argumentos sobre vários aspectos, com particular realce para a escolha da(s) língua(s) oficial(is), Português/línguas bantu, que garantam um ambiente político harmonioso (LOPES, 1997, 2004; FIRMINO, 2002, entre outros). Assim, estudos sobre a comunidade moçambicana 
bilíngue propriamente ditos são escassos, considerando-se o estudo realizado mais recentemente por Langa (no Prelo) sobre "usos linguísticos da comunidade moçambicana bilíngue". Neste estudo, Langa (no Prelo) argumenta que, no que se refere ao "padrão de escolha" no nível dos interlocutores, o Português parece ser a língua de comunicação preferida pelos inquiridos nos seus relacionamentos fora do contexto familiar, nos quais as línguas bantu é que são mais usadas. Contudo, os resultados relativos aos interlocutores dos grupos de Amizades e/ou Relacionamentos e Desconhecidos parecem apontar para um uso considerável das línguas bantu fora do contexto familiar por esta geração pós-independência. Quanto ao "padrão de escolha" no nível dos contextos de utilização, verifica-se que a percentagem de alternativas relativas ao Português/L2 representa o dobro das que foram assinaladas para a LB/L1. Estes resultados mostram claramente a prevalência do uso do Português tanto em contexto formal como informal pela geração do pós-independência.

As atitudes linguísticas são vistas como englobando diversas dimensões “(...) desde as atitudes com relação a variedades linguísticas/dialetais e estilos de fala, passando pelas atitudes com relação ao aprendizado de uma língua, até as atitudes com relação a grupos, comunidades, minorias, entre outras dimensões" (CORBARI, 2013, p.61).

Na multiplicidade das áreas de abrangência do conceito de atitudes linguísticas, neste estudo corrobora-se com o posicionamento apresentado por BEM (1973, p. 29), citado por Corbari (2013, p.61), segundo o qual

atitudes são os gostos e as antipatias. São as nossas afinidades e aversões a situações, objetos, grupos ou quaisquer aspectos identificáveis do nosso meio, incluindo ideias abstratas e políticas sociais. [...] nossos gostos e antipatias têm raízes nas nossas emoções, no nosso comportamento e nas influências sociais que são exercidas sobre nós. Mas também repousam em bases cognitivas. (CORBARI, 2013, p.61),

CORBARI (2013, p.63) acrescenta que

[...], a atitude linguística de um indivíduo resultaria da soma de suas crenças e conhecimentos, seus afetos (sentimentos ou emoções) e sua tendência a se comportar de determinada forma diante da língua ou de uma situação sociolinguística. (CORBARI, 2013, p.63)

Assim, ao se buscar entender as percepções em relação ao uso do Português e da língua materna bantu, está-se perante uma busca da percepção de atitudes linguísticas da comunidade moçambicana bilíngue. 
O conceito de atitude linguística está ligado ao de identidade linguística. Tal como o primeiro, este conceito é também complexo e pode ser visto sob vários prismas de análise e está associado à história sincrónica e diacrónica do Homem (DA SILVA, 2000). Por exemplo, Ishiki (2013) discute o conceito de identidade linguística sob o prisma de ensino de língua de herança, em que destaca o impacto da experiência do ensino de línguas estrangeiras no conflito de participação, negociação e transformação da identidade. Gafaranga (2001) analisa a alternância linguística entre falantes bilíngues e sugere que este fenómeno, mais do que ser o resultado de uma prática social, é, sobretudo, uma questão de identidade linguística, pois é um mecanismo que confere a pertença de um indivíduo a um dado grupo. O presente artigo adopta o conceito de identidade apresentado e usado por Gee (2000). Este defende que identidade é ser reconhecido como um certo tipo de pessoa (kind of person) num dado contexto. Essas formas de ver identidade incluem as formas desenvolvidas pela força (na natureza), autoridade (entre instituições), reconhecimento pelo seu discurso (de/entre indivíduos) e partilha de certas práticas (afinidade de grupo). Dessas diferentes formas de ver a identidade, o presente estudo foca a identidade natural, que é basicamente a resposta à pergunta "quem eu sou?". A resposta a esta pergunta dá a pertença da pessoa, fenómeno em relação ao qual a pessoa visada não tem controlo, pela força da natureza ou naturalmente pertence a esse grupo (linguístico ou identitário).

\section{Apresentação e discussão dos dados}

Como se referiu anteriormente, o estudo visa a aferir atitudes e identidades linguísticas da comunidade moçambicana bilíngue através da recolha de percepções em relação ao uso do Português e da sua língua materna bantu. Assim, a secção está organizada em duas grandes partes, sendo a primeira a relativa à auto avaliação dos inquiridos em relação ao uso do Português e da língua bantu e, a segunda parte, sobre a identidade, no sentido kind of person (GEE, 2000), dos inquiridos em relação ao uso das mesmas línguas.

Nesta secção, os dados são apresentados em tabelas. Estas se apresentam de duas formas, sendo (i) uma geral, a que apresenta os dados gerais ou globais das três cidades em estudo (Maputo, Xai-Xai e Quelimane) e (ii) a detalhada, a que apresenta os dados por cidade. As tabelas referentes a dados globais ou gerais, por exemplo a Tabela 1, apresentam as variáveis do "tipo de resposta" agregadas, por exemplo, as variáveis "totalmente de acordo" e "de acordo" ou "totalmente em desacordo" e em "desacordo" encontram-se agregadas em "(Tot)acordo" e "(tot)desacordo", respectivamente ao passo que as tabelas referentes a dados 
detalhados por cidade, as suas variáveis não se encontram agregadas. O objectivo desta organização prende-se ao facto de se pretender captar as possíveis nuances das respostas dos inquiridos por cidade.

\subsection{Atitudes linguísticas da comunidade moçambicana bilíngue}

De uma forma geral, grande parte dos inquiridos auto avaliam-se positivamente em relação ao uso do Português/L2, conforme a tabela 1:

Tabela 1: Auto-avaliação Global Português L2

\begin{tabular}{l|l|l|l|l|l}
\hline Tipo de resposta & $\begin{array}{l}\text { Orgulhoso/a } \\
\%\end{array}$ & $\begin{array}{l}\text { Mais } \\
\text { inteligente \% }\end{array}$ & $\begin{array}{l}\text { Pessoa } \\
\text { instruída \% }\end{array}$ & $\begin{array}{l}\text { Pessoa } \\
\text { civilizada \% }\end{array}$ & Envergonhado/a \% \\
\hline (Tot) acordo & 77.1 & 61.5 & 73.7 & 58.5 & 14.4 \\
\hline Indeciso & 8.5 & 9.6 & 10.4 & 12.6 & 8.5 \\
\hline (Tot) desacordo & 10.3 & 20.7 & 9.6 & 24.1 & 72.2 \\
\hline $\mathrm{N} / \mathrm{R}$ & 4.1 & 8.1 & 6.3 & 4.8 & 4.8 \\
\hline Total & 100 & 100 & 100 & 100 & 100 \\
\hline
\end{tabular}

No geral, os inquiridos consideram que, quando usam a LP, sentem-se orgulhosos, mais inteligentes, instruídos e pessoas civilizadas, por isso não têm vergonha ou têm atitudes positivas em relação a essa língua. Este panorama geral de auto avaliação dos inquiridos abona a favor da vitalidade da LP, aliás, como se esperava que fosse, tendo em consideração a política linguística adoptada no país, que toma a LP como a oficial, a única que aparece explicitamente referenciada na Constituição da República de Moçambique do País, bem como as políticas de ensino de línguas adoptadas no país desde a sua independência até 2003, altura em que oficialmente se introduz o ensino bilíngue (envolvendo a LP e as LBs) a título experimental. A auto-avaliação geral positiva dos inquiridos não apresenta nuances significativas por cidades de estudo, conforme se mostra na Tabela 2:

Tabela 2: Auto-avaliação por cidade do Português L2

\begin{tabular}{l|l|l|l|l|l|l}
\hline \multirow{2}{*}{ Tipo de resposta } & \multicolumn{2}{l}{ Sente-se orgulhoso/A (D19.A) } & \multicolumn{3}{l}{ Sente-se mais inteligente (D19.B) } \\
\cline { 2 - 8 } & Maputo & Xai-Xai & Quelimane & Maputo & Xai-Xai & Quelimane \\
\hline Totalmente de acordo & 18.8 & 34.9 & 35.2 & 9.4 & 18.6 & 21.6 \\
\hline De acordo & 49.0 & 44.2 & 50.0 & 46.9 & 40.7 & 47.7 \\
\hline Indeciso & 12.5 & 8.1 & 4.5 & 10.4 & 11.6 & 6.8 \\
\hline Em desacordo & 5.2 & 4.7 & 3.4 & 15.6 & 15.1 & 10.2 \\
\hline Totalmente em desacordo & 8.3 & 4.7 & 4.5 & 8.3 & 7.0 & 5.7 \\
\hline
\end{tabular}




\begin{tabular}{|c|c|c|c|c|c|c|}
\hline$N / R$ & 6.3 & 3.5 & 2.3 & 9.4 & 7.0 & 8.0 \\
\hline \multirow[t]{2}{*}{ Total } & 100 & 100 & 100 & 100 & 100 & 100 \\
\hline & \multicolumn{3}{|c|}{ Uma pessoa instruída (D19.C) } & \multicolumn{3}{|c|}{ Uma pessoa civilizada (D19 D) } \\
\hline Totalmente de acordo & 17.7 & 30.2 & 27.3 & 21.9 & 23.3 & 29.5 \\
\hline De acordo & 54.2 & 47.7 & 44.3 & 28.1 & 41.9 & 31.8 \\
\hline Indeciso & 12.5 & 7.0 & 11.4 & 15.6 & 9.3 & 12.5 \\
\hline Em desacordo & 6.3 & 7.0 & 5.7 & 16.7 & 14.0 & 11.4 \\
\hline Totalmente em desacordo & 3.1 & 3.5 & 3.4 & 12.5 & 5.8 & 11.4 \\
\hline$N / R$ & 6.3 & 4.7 & 8.0 & 5.2 & 5.8 & 3.4 \\
\hline \multirow[t]{2}{*}{ Total } & 100 & 100 & 100 & 100.0 & 100.0 & 100.0 \\
\hline & \multicolumn{3}{|c|}{ Envergonhado/a (D19.I) } & & & \\
\hline Totalmente de acordo & 1.0 & 5.8 & 4.5 & & & \\
\hline De acordo & 12.5 & 9.3 & 10.2 & & & \\
\hline Indeciso & 12.5 & 3.5 & 9.1 & & & \\
\hline Em desacordo & 28.1 & 32.6 & 28.4 & & & \\
\hline Totalmente em desacordo & 39.6 & 44.2 & 44.3 & & & \\
\hline $\mathrm{N} / \mathrm{R}$ & 6.3 & 4.7 & 3.4 & & & \\
\hline Total & 100 & 100 & 100 & & & \\
\hline
\end{tabular}

Independentemente da diversidade dos perfis sócio-políticos das cidades em estudo (Maputo, Xai-Xai, Quelimane), os inquiridos sentem-se bem usando a LP, como mostra o facto de a grande maioria dos mesmos (acima de 75\%) preferirem essa língua.

Sobre a auto-avaliação em relação ao uso das LB/L1, no geral, as percepções dos inquiridos já não são claramente positivas, conforme se mostra na Tabela 3:

Tabela 3: Auto-avaliação Global de L1 bantu

\begin{tabular}{l|l|l|l|l|l}
\hline Tipo de resposta & Orgulhoso/a \% & $\begin{array}{l}\text { Mais } \\
\text { inteligente \% }\end{array}$ & $\begin{array}{l}\text { Pessoa não } \\
\text { civilizada \% }\end{array}$ & $\begin{array}{l}\text { Envergo-nhado/a } \\
\%\end{array}$ & $\begin{array}{l}\text { Tribalista } \\
\text { regionalista \% }\end{array}$ \\
\hline (Tot) acordo & 73.0 & 45.2 & 8.1 & 7.4 & 23.7 \\
\hline Indeciso & 3.3 & 13.7 & 3.0 & 5.2 & 9.6 \\
\hline (Tot) desacordo & 9.6 & 27.8 & 84.4 & 83.7 & 60.0 \\
\hline N/R & 14.1 & 13.3 & 4.4 & 3.7 & 6.7 \\
\hline Total & 100 & 100 & 100 & 100 & 100 \\
\hline
\end{tabular}

Grande parte dos inquiridos (73\%) sente-se orgulhosa quando fala uma LB, mas apenas uma percentagem considerável dos mesmos (45.2\%) se sente mais inteligente quando fala a sua língua materna. O sentimento de orgulho está intimamente associado ao sentimento de pertença aos seus grupos étnicos por isso sentem-se orgulhosos em ser Changana, para Xai-Xai, Chuwabo ou Lomwe, para Quelimane e Changana ou Ronga, para Maputo. Comparando o sentimento de "orgulhoso/a" e o de "mais inteligente" nas duas línguas, os dados sugerem que, apesar de os inquiridos se sentirem mais favoráveis ao sentimento de orgulho em relação à LB, sentem-se mais inteligentes quando falam a LP. Isto pode significar uma manifestação de um preconceito 
em relação as LB, no sentido de que estas não são apropriadas para a transmissão da inteligência, o que pode afectar a motivação para as transmitirem de uma geração para a outra. Este sentimento de menos inteligente em relação ao uso da LB pode não abonar a favor da manutenção das LBs a longo prazo. Apesar de não se sentirem mais inteligentes ao usarem uma LB, ao discordarem das afirmações segundo as quais, falar/usar uma LB remete ao sentimento de "pessoa não civilizada", "envergonhado/a" e o de "tribalista ou regionalista", os inquiridos marcam a sua própria política linguística positiva em relação às suas LBs, pois sentem-se orgulhosos, civilizados e não tribalistas ou regionalistas quando falam estas línguas. Estes dados gerais são consistentes com as constatações por cidade, conforme se pode ver na Tabela 4:

Tabela 4: Auto avaliação por cidade de L1 bantu

\begin{tabular}{|c|c|c|c|c|c|c|}
\hline \multirow{2}{*}{ Tipo de resposta } & \multicolumn{3}{|c|}{ Orgulhoso/a (D20.A) } & \multicolumn{3}{|c|}{ Mais inteligente (D20.B) } \\
\hline & Maputo & Xai-Xai & Quelimane & Maputo & Xai-Xai & Quelimane \\
\hline Totalmente de acordo & 30.2 & 45.3 & 56.8 & 12.5 & 14.0 & 20.5 \\
\hline De acordo & 40.6 & 23.3 & 22.7 & 25.0 & 33.7 & 30.7 \\
\hline Indeciso & 3.1 & 5.8 & 1.1 & 13.5 & 16.3 & 11.4 \\
\hline Em desacordo & 7.3 & 9.3 & 2.3 & 26.0 & 19.8 & 13.6 \\
\hline Totalmente em desacordo & 5.2 & 3.5 & 1.1 & 11.5 & 4.7 & 6.8 \\
\hline$N / R$ & 13.5 & 12.8 & 15.9 & 11.5 & 11.6 & 17.0 \\
\hline \multirow[t]{2}{*}{ Total } & 100 & 100 & 100 & 100 & 100 & 100 \\
\hline & \multicolumn{3}{|c|}{ Envergonhado/a (D20.H) } & \multicolumn{3}{|c|}{ Uma pessoa não civilizada (D20.G) } \\
\hline Totalmente de acordo & 1.0 & 1.2 & 5.7 & 0.0 & 2.3 & 8.0 \\
\hline De acordo & 3.1 & 4.7 & 6.8 & 5.2 & 5.8 & 3.4 \\
\hline Indeciso & 4.2 & 9.3 & 2.3 & 1.0 & 4.7 & 3.4 \\
\hline Em desacordo & 28.1 & 27.9 & 18.2 & 28.1 & 27.9 & 21.6 \\
\hline Totalmente em desacordo & 58.3 & 53.5 & 64.8 & 59.4 & 54.7 & 61.4 \\
\hline $\mathrm{N} / \mathrm{R}$ & 5.2 & 3.5 & 2.3 & 6.3 & 4.7 & 2.3 \\
\hline \multirow[t]{2}{*}{ Total } & 100 & 100 & 100 & 100 & 100 & 100 \\
\hline & \multicolumn{3}{|c|}{ Um/a tribalista ou regionalista (D20.F) } & & & \\
\hline Totalmente de acordo & 2.1 & 9.3 & 12.5 & & & \\
\hline De acordo & 14.6 & 22.1 & 11.4 & & & \\
\hline Indeciso & 6.3 & 4.7 & 18.2 & & & \\
\hline Em desacordo & 35.4 & 23.3 & 31.8 & & & \\
\hline Totalmente em desacordo & 32.3 & 31.4 & 25.0 & & & \\
\hline $\mathrm{N} / \mathrm{R}$ & 9.4 & 9.3 & 1.1 & & & \\
\hline Total & 100 & 100 & 100 & & & \\
\hline
\end{tabular}

Em relação ao sentimento de orgulho, apesar de, nas três cidades em estudo, grande parte dos inquiridos auto avaliarem-se positivamente, destaca-se a avaliação "totalmente de 
acordo" das mesmas, que é considerável em Maputo (30.2\%), cerca da metade em Xai-Xai (45.3\%) e grande parte dos inquiridos (56.8\%), em Quelimane. Comparando a mesma variável na LB e na LP, nota-se que a avaliação é mais convicta em relação à LB do que à LP em relação ao sentimento de orgulho. Da mesma forma que, nas três cidades, os inquiridos sentem-se muito convictos ("totalmente em desacordo") em relação à afirmação de que não se sentem envergonhados, tribalistas ou regionalistas nem não civilizados quando falam as suas LBs. Contudo, não estão convictos em relação ao sentimento de mais inteligentes.

Nas três cidades, em relação à auto avaliação da comunidade moçambicana bilíngue, em relação ao uso da LP/L2 e da LB/L1, os dados mostram que os inquiridos se sentem orgulhosos, pessoas civilizadas e reconhecem a diversidade étnico-linguística do país, ao não considerarem obstáculo (não se sentem tribalistas ou regionalistas) a pertença a um grupo étnico específico. Contudo, é preciso desenvolver acções que elevem os níveis de confiança dessa comunidade em relação ao uso da LB na transmissão da ciência e tecnologia de modo a que também se sintam "(mais) inteligentes" ao usarem as LBs, i.e., de modo a convencê-las de que as LB são também línguas de transmissão de ciência e tecnologia e assim as pessoas sentirem (mais) inteligentes quando as usam. Esse desiderato poderá ser alcançado com o contínuo uso das LBs em espaços comummente associados à LP (Langa, no Prelo), incluindo na instrução formal, nas instituições do governo, etc. Esta auto avaliação dos inquiridos deixa um cenário fértil para a manutenção das LBs, garantindo consequentemente a sua vitalidade. Contudo, também deixa um alerta para o contínuo desenvolvimento de acções conducentes ao reconhecimento e uso das LBs por esta geração por forma a garantir a transmissão das mesmas para as futuras gerações.

\subsection{Identidade linguística da comunidade moçambicana bilíngue}

Na presente secção apresenta-se questões relacionadas com a identidade linguística (cf. GEE, 2000).

Tabela 5: Identidade global do sentimento de cidadã(o) Português L2

\begin{tabular}{l|l|l|l|l}
\hline $\begin{array}{l}\text { Tipo de } \\
\text { resposta }\end{array}$ & $\begin{array}{l}\text { Superior a outros } \\
\text { moçambicanos que não falam } \\
\text { esta língua } \\
\%\end{array}$ & $\begin{array}{l}\text { Menos } \\
\text { moçambicano/a } \\
\%\end{array}$ & $\begin{array}{l}\text { Como um(a) cidadão(ã) } \\
\text { português/a } \\
\%\end{array}$ & $\begin{array}{l}\text { Estrangeiro/a no } \\
\text { seu próprio país } \\
\%\end{array}$ \\
\hline (Tot) acordo & 18.5 & 32.6 & 24.8 & 20.4 \\
\hline Indeciso & 4.8 & 10.0 & 6.3 & 7.0 \\
\hline $\begin{array}{l}\text { (Tot) } \\
\text { desacordo }\end{array}$ & 71.5 & 50.0 & 63.7 & 64.4 \\
\hline
\end{tabular}




\begin{tabular}{l|l|l|l|l}
\hline $\mathrm{N} / \mathrm{R}$ & 5.2 & 7.4 & 5.2 & 8.1 \\
\hline Total & 100 & 100 & 100 & 100 \\
\hline
\end{tabular}

De uma forma geral, grande parte dos inquiridos (71.5\%) não se sentem superiores aos outros moçambicanos que não falam a LP quando usam esta língua e um pouco mais da metade dos mesmos não se sentem "menos moçambicano/a", não se sente "como um(a) cidadão(ã) português(a) nem como "estrangeiro no seu próprio país". Esses dados mostram que, claramente, a LP é nativizada ou assumida como uma língua moçambicana, corroborando com a afirmação de Firmino (2002, p. 201) segundo a qual “(...) as manipulações do Português e das ideologias às quais elas estão ligadas, reflectem a incorporação da língua nas actividades sociais [na zona central] e os tipos de relações sociais associadas a ela". Assim, a LP é uma língua identitária para os moçambicanos. Os dados por cidade confirmam esta tendência, como se pode ver na Tabela 6:

Tabela 6: Identidade por cidade do sentimento de cidadã(o) Português L2

\begin{tabular}{|c|c|c|c|c|c|c|}
\hline \multirow{2}{*}{ Tipo de resposta } & \multicolumn{3}{|c|}{$\begin{array}{l}\text { Superior a outros moçambicanos que não } \\
\text { falam esta língua (D19. E) }\end{array}$} & \multicolumn{3}{|c|}{ Menos moçambicano/a (D19.G) } \\
\hline & Maputo & Xai-Xai & Quelimane & Maputo & Xai-Xai & Quelimane \\
\hline Totalmente de acordo & 2.1 & 9.3 & 10.2 & 9.4 & 8.1 & 11.4 \\
\hline De acordo & 5.2 & 12.8 & 17.0 & 16.7 & 12.8 & 17.0 \\
\hline Indeciso & 2.1 & 5.8 & 6.8 & 7.3 & 11.6 & 20.5 \\
\hline Em desacordo & 32.3 & 27.9 & 19.3 & 24.0 & 31.4 & 26.1 \\
\hline Totalmente em desacordo & 50.0 & 38.4 & 45.5 & 32.3 & 27.9 & 20.5 \\
\hline $\mathrm{N} / \mathrm{R}$ & 8.3 & 5.8 & 1.1 & 10.4 & 8.1 & 4.5 \\
\hline \multirow[t]{2}{*}{ Total } & 100 & 100 & 100 & 100 & 100 & 100 \\
\hline & \multicolumn{3}{|c|}{$\begin{array}{l}\text { Sente-se como um/a cidadão/ã português/a } \\
\text { (D19. H) }\end{array}$} & \multicolumn{3}{|c|}{$\begin{array}{l}\text { Sente-se estrangeiro/a no seu próprio país } \\
\text { (D19. J) }\end{array}$} \\
\hline Totalmente de acordo & 8.3 & 5.8 & 10.2 & 8.3 & 3.5 & 9.1 \\
\hline De acordo & 8.3 & 27.9 & \begin{tabular}{|l|}
14.8 \\
\end{tabular} & 10.4 & 15.1 & \begin{tabular}{|l|}
14.8 \\
\end{tabular} \\
\hline Indeciso & 5.2 & 4.7 & 9.1 & 6.3 & 9.3 & 5.7 \\
\hline Em desacordo & 30.2 & 29.1 & 26.1 & 25.0 & 27.9 & 21.6 \\
\hline Totalmente em desacordo & 41.7 & 27.9 & 35.2 & 41.7 & 38.4 & 38.6 \\
\hline $\mathrm{N} / \mathrm{R}$ & 6.3 & 4.7 & 4.5 & 8.3 & 5.8 & 10.2 \\
\hline Total & 100 & 100 & 100 & 100 & 100 & 100 \\
\hline
\end{tabular}

Ainda que os pressupostos do estudo na escolha das cidades tenham sido (i) heterogeneidade linguística, com tendência a assimilacionista (Maputo), (ii) homogeneidade linguística (Xai-Xai) e (iii) tendência assimilacionista (Quelimane) e por isso se esperavam posturas diferentes em relação ao uso da LP ou LBs, os dados mostram que, nas três cidades, os 
inquiridos identificam-se com o uso da LP. Contudo, isso não faz deles cidadãos portugueses só porque se auto avaliam falarem a LP, nem estrangeiros em Moçambique, uma vez que a grande parte dos inquiridos (+ de 55\%) respondeu estar em des(acordo).

A auto avaliação da identidade linguística em relação à LB é consistente em relação à LP, conforme se pode ver na Tabela 7 :

Tabela 7: Identidade global do sentimento de cidadã(o) L1 bantu

\begin{tabular}{l|l|l}
\hline Tipo de resposta & $\begin{array}{l}\text { Superior a outros jovens do seu grupo } \\
\text { etnolinguístico que não falam esta língua } \\
\%\end{array}$ & $\begin{array}{l}\text { Um(a) moçambicano(a) mais } \\
\text { genuíno(a) } \\
\%\end{array}$ \\
\hline (Tot) acordo & 23.7 & 64.4 \\
\hline Indeciso & 9.6 & 10.4 \\
\hline (Tot) desacordo & 60.0 & 20.7 \\
\hline $\mathrm{N} / \mathrm{R}$ & 6.7 & 4.4 \\
\hline Total & 100 & 100 \\
\hline
\end{tabular}

De uma forma geral, grande parte dos inquiridos (60\%) está em desacordo com a afirmação segundo a qual se sente "superior a outros jovens do seu grupo etnolinguístico que não falam esta língua [LB])". Este sentimento pode significar que os inquiridos não se sentem superiores nem inferiores ao se definirem como são, i.e., naturalmente pertencem ao dado grupo étnico (ex: Ronga, Changana, Chuwabo ou Lomwe) e essa pertença a esse grupo não constituiu uma opção dos inquiridos. Contudo, a grande maioria dos inquiridos (64.4\%), ao estarem de acordo com a afirmação segundo a qual quando usa a LB/L1 se sente "um(a) moçambicano(a) mais genuíno(a)", parecem estar a reconhecer que a LB é a língua que naturalmente ressalta a identidade dos nativos como moçambicanos. Por outras palavras, uma pessoa genuinamente moçambicana deve falar, pelo menos, uma língua bantu. Estes dados gerais são consistentes com os das três cidades discriminadas, conforme a Tabela 8:

Tabela 8: Identidade por cidade do sentimento de cidadã(o) L1 bantu

\begin{tabular}{l|l|l|l|l|l|l}
\hline \multirow{2}{*}{ Tipo de resposta } & \multicolumn{2}{l}{$\begin{array}{l}\text { SUPERIOR A OUTROS JOVENS do seu grupo } \\
\text { etnolinguístico que não falam esta língua } \\
\text { (D20.C) } \%\end{array}$} \\
& $\begin{array}{l}\text { UENUINO (D20.E) } \\
\%\end{array}$ \\
\cline { 2 - 8 } & Maputo & Xai-Xai & Quelimane & Maputo & Xai-Xai & Quelimane \\
\hline Totalmente de acordo & 11.5 & 17.4 & 26.1 & 20.8 & 29.1 & 39.8 \\
\hline De acordo & 19.8 & 20.9 & 19.3 & 38.5 & 39.5 & 26.1 \\
\hline Indeciso & 3.1 & 2.3 & 12.5 & 8.3 & 8.1 & 14.8 \\
\hline Em desacordo & 29.2 & 31.4 & 20.5 & 15.6 & 10.5 & 14.8 \\
\hline Totalmente em desacordo & 29.2 & 23.3 & 20.5 & 11.5 & 7.0 & 2.3 \\
\hline
\end{tabular}




\begin{tabular}{l|l|l|l|l|l|l|}
\hline $\mathrm{N} / \mathrm{R}$ & 7.3 & 4.7 & 1.1 & 5.2 & 5.8 & 2.3 \\
\hline Total & 100 & 100 & 100 & 100 & 100 & 100 \\
\hline
\end{tabular}

Ainda que, de uma forma geral, a grande maioria dos inquiridos não se sintam superiores aos outros que não falam a LB, os dados de Xai-Xai e Quelimane revelam que uma percentagem relativamente reduzida $(17.4 \%$ e $26.1 \%$, respectivamente) se sentem superiores aos outros jovens do seu grupo etnolinguístico que não falam a sua LB. Esse dado reforça a percepção segundo a qual, apesar de todos serem moçambicanos e se sentirem falantes do Português, como uma língua também moçambicana, há uma necessidade de uma língua que genuinamente os ligue à sua etnia no seu país, por isso em todas as cidades se condiciona falar uma língua bantu ao estatuto de ser genuinamente moçambicano.

\section{Conclusões}

As atitudes dos inquiridos são favoráveis à LP mas manifestam o desejo de preservar/manter a sua LB. Sentem-se civilizados falando uma ou a outra língua, portanto, falar a LP ou a LB tem pouco a ver com o facto de os falantes se sentirem ou não civilizados. Da mesma forma, os inquiridos não se sentem tribalistas por falarem a sua língua LB, contudo tendem a considerar menos inteligentes os que não falam a LP. Este dado é revelador no que tange a acções a desenvolver em prol das LBs, como, por exemplo: o seu contínuo uso na educação formal (ensino bilíngue), uso nos espaços públicos oficiais ou de estado, e outros locais comummente associados ao domínio da LP. Essas acções podem elevar paulatinamente a autoestima dos falantes, bem como reduzir pouco a pouco a barreira historicamente construída sobre estas línguas, o que levou ao preconceito linguístico contra LBs.

Embora os inquiridos sejam mais favoráveis às LBs, afirmaram sentirem-se orgulhosos com elas e estas serem um marco da sua identidade, o seu preconceito em relação a veiculação da instrução e da inteligência nas/através destas línguas pode minar a manutenção linguística das mesmas nas próximas gerações (i.e., podem não se sentir motivados a ensinar as suas LB/L1 aos seus filhos), o que pode afectar negativamente a longevidade das mesmas, dando assim origem ao declínio e abandono das mesmas.

De um modo geral, tanto o uso da LP/L2 como da LB/L1 são avaliados positivamente pelos inquiridos, apontando assim para uma geração que convive de forma harmoniosa com o seu bilinguismo. Quanto à identidade político-cultural, mais especificamente, os inquiridos não se sentem discriminados como cidadãos moçambicanos pelo facto de falarem Português, mas 
tendem a considerar que o domínio de uma língua bantu os torna cidadãos mais genuinamente moçambicanos.

Assim, quanto ao objectivo de averiguar se o bilinguismo em Moçambique está, ou não, a dar origem ao declínio e abandono das línguas bantu locais, pode-se afirmar, com algum cuidado, que o bilinguismo não está a dar origem ao declínio nem ao abandono das línguas locais. Contudo, é preciso que se continue a desenvolver acções de modo a que os falantes tenham atitudes positivas das suas línguas maternas a par da língua portuguesa, revertendo assim a "erosão ambiental" em favor das duas línguas (LP e LB) e a vitalidade das LBs.

\section{REFERÊNCIAS}

ASHBY, Simone e BARBOSA, Sílvia. Bantu substratum interference in Mozambican Portuguese speech varieties. Africana Linguistica, 17. 2011, p. 3-31.

BATIBO, Herman. Language decline and death in Africa: Causes, consequences and challenges. Toronto: MULTILINGUAL MATTERS. 2012.

BLOOMFIELD, Leonard. Language. New York: Henry Holt. 1933.

CHIMBUTANE, Feliciano. Panorama linguístico de Moçambique: Análise dos dados do III Recenseamento Geral da População e Habitação de 2007. Maputo: INSTITUTO NACIONAL DE ESTATÍ́STICA. 2012.

CORBARI, Clarice. Atitudes linguísticas: um estudo nas localidades paranaenses de Irati e Santo Antônio do Sudoeste. Tese de Doutoramento. Salvador: Universidade Federal da Bahia. 2013.

DA SILVA, Tomaz.(ed.). Identidade e diferença: a perspectiva dos estudos culturais. Petrópolis: EDITORA VOZES. 2000.

DIAS, Hildizina. Saberes docentes e formação de professores na diversidade cultural. Maputo: IMPRENSA UNIVERSITÁRIA. 2008.

DIAS, Hildizina. Minidicionário de Moçambicanismos. Maputo: FURTADO \& GODINGO. 2002.

FIRMINO, Gregório. A "questão linguística" na África pós-colonial: O caso do português e das línguas autóctones em Moçambique. Maputo: Promédia. 2002.

FIRMINO, Gregório. Situação linguística de Moçambique: Dados do II Recenseamento Geral da População e Habitação de 1997. Maputo: INSTITUTO NACIONAL DE ESTATÍSTICA. 2000.

FISHMAN, Joshua. Bilingualism with and without diglossia; diglossia with and without bilingualism. Journal of Social Issues, 23 (2). 1967, p. 29-38.

FISHMAN, Joshua. Who speaks what language to whom and when? La Linguistique, 2. 1965, p. 67-88.

GAFARANGA, Joseph. Linguistic identities in talk-in-interaction: Order in bilingual conversation. Journal of Pragmatics 33.(2001, p. 1901-1925

GEE, James. Identity as an analytic lens for research in education. Review of research education, Vol.25. 2000, p. 99-125.

GUISSEMO, Manuel. Manufacturing multilingualisms of marginality in Mozambique: exploring the orders of visibility of local african languages. Stockholm: SROCKHOLM UNIVERSITY. 2018. 
GONÇALVES, Perpétua. A génese do Português de Moçambique. Lisboa: IMPRENSA NACIONAL/CASA DA MOEDA. 2010

GONÇALVES, Perpétua. Towards a unified vision of classes of language acquisition and change: Arguments from the genesis of Mozambican African Portuguese. Journal of Pidgin and Creole Languages, 19 (2), 2004, p. 225-259.

GONÇALVES, Perpétua, LANGA, David \& TEMBE, Félix. Panorama da comunidade moçambicana bilíngue Língua Bantu/L1-Português/L2: Fase Piloto. Maputo, Universidade Eduardo Mondlane. Relatório de investigação (não publicado). 2014.

INSTITUTO NACIONAL DE ESTATístICA (INE). Dados do Recenseamento Geral da População de 2007, 2009, 2019. http://www.ine.gov.mz.

INTERNATIONAL STANDARD CLASSIFICATION OF EDUCATION (ISCED). Montreal, Quebec: UNESCO - Institute for Statistics. 2011.

ISHIKI, Naho. Negotiation of Identity: (re)construction and (re)positioning of self through language learning. Indonesian Journal of Applied Linguistics, Vol. 3, No 1.2013, Fp, 39-53.

LAFON, Michael. Educação Bilíngue Em Moçambique: Interesse Popular Ultrapassa a Timidez do Programa. In: CHIMBUTANE, F. e STROUND, C. (orgs) Educação Bilíngue em Moçambique: Reflectindo Criticamente sobre Políticas e Práticas. Maputo: TEXTO EDITORES, 2011, p.13-34.

LANGA, David. Usos linguísticos da comunidade moçambicana bilíngue. In Siopa, C., Marques, J. A., Monteiro, A.C. \& Serra, P. (eds), Língua e literacia(s) no século XXI: Textos selecionados das 9as Jornadas da Língua Portuguesa. Porto: PORTO EDITORA. 2019, p. 99-126.

LOPES, Armando. Política linguística: princípios e problemas/Language police: principles and problems. Maputo: IMPRENSA UNIVERSITÁRIA. 1997.

LOPES, Armando. A batalha das línguas: Perspectivas sobre linguística aplicada em Moçambique. Maputo: IMPRENSA UNIVERSITÁRIA. 2004.

LOPES, Armando; SITOE, Salvador e NHAMUENDE, Paulino. Moçambicanismos: Para um léxico de usos do Português Moçambicano. Maputo: IMPRENSA UNIVERSITÁRIA. 2002.

MACHUNGO, Inês. Neologismos do Português de Moçambique. Maputo: IMPRENSA UNIVERSITÁRIA. 2016.

MOHANTY, Ajit e PERREGAUX, Christiane. Language acquisition and bilingualism. In: JOHN, Berry, PIERE, Dasen e SARASWATHI. T.S. (eds) Handbook of cross-cultural psychology, Vol. 2: Basic processes and human development. $2^{\text {nd }}$ edition. Needham Heights, MA: ALLYN \& BACON. 1997, p. 217-253.

NELIMO. I Seminário Sobre A Padronização da Ortografia das Línguas Moçambicanas. Maputo: EDITORA ESCOLAR. 1989

NGUNGA, Armindo. Interferências de línguas moçambicanas em Português falado em Moçambique. Revista Científica da UEM: Série Letras e Ciências Sociais, Edição Especial de Lançamento, № Zero. 2012, p. 7-20.

NGUNGA, Armindo. Introdução à Linguística Bantu. Maputo: IMPRENSA UNIVERSITÁRIA. 2004.

NGUNGA, Armindo e FAQUIR, Osvaldo. (eds). Padronização da Ortografia de Línguas Moçambicanas: Relatório do III Seminário. Maputo: CENTRO DE ESTUDOS AFRICANOS (CEA). 2011.

NGUNGA, Armindo e BAVO, Názia. Práticas linguísticas em Moçambique: Avaliação da vitalidade linguística em seis distritos. Maputo: CENTRO DOS ESTUDOS AFRICANOS (CEA) - UNIVERSIDADE EDUARDO MONDLANE (UEM). 2011.

PAUWELS, Anne. Language maintenance. In: DAVES, Alan e CATHERINE, Elder (eds.), The handbook of Applied Linguistics. Oxford: BLACKWELL. 2004, p. 719-734.

REPÚBLICA DE MOÇAMBIQUE. Constituição da República (actualizada). Maputo: IMPRENSA NACIONAL DE MOÇAMBIQUE. 2004 
ROMAIN, Suzanne. Bilingualism. Oxford: BLACKWELL. 1995.

SITOE, Bento. Empréstimos lexicais do Português no Tsonga. Revista Internacional de Língua Portuguesa, 5/6. 1991, p. 106-113.

SITOE, Bento e NGUNGA, Armindo. (eds) Relatório do /l Seminário sobre a Padronização das Línguas Moçambicanas. Maputo: EDITORA ESCOLAR. 2000.

SKUTNABB-KANGAS, Tove. Bilingualism or not: The education of minorities. Clevedon/UK: MULTILINGUAL METTERS. 1981.

Recebido em 05/10/2019

e aprovado em 22/11/2019. 